\section{COAGULATION OF THE BLOOD}

Human Blood Coagulation and Its Disorders

By Dr. Rosemary Biggs and Dr. R. G. Maefarlane. Third edition. Pp. xxiv +474 . (Oxford: Blackwell Scientific Publications, 1962.) 52s. 6d. net.

THE five years since the last edition of this book have brought a greater clarity to the field of blood coagulation: it has not been necessary to postulate the existence of any new clotting factors, but much light has been shed on the inter-relationships of those factors the existence of which in normal blood is now firmly estab. lished. Important recent work has been concerned with the activation of the coagulation mechanism by contact of blood with glass and other foreign surfaces, the changes which platelets undergo during clotting, the relationship of thrombosis to coagulation and the fibrinolytic system. All these developments are lucidly and critically discussed in the new and extensively revised edition of this excellent book.

The form of the book remains unaltered: the first part is devoted to the theoretical aspects of human blood coagulation and the second to the diagnosis and treatment of coagulation defects. There is an excellent new introductory chapter to the second part which will enhance the value of the book to the practising physician and clinical pathologist, and the technical appendix has been amplified. The most important practical advance in the treatment of blood coagulation disorders in recent years has been the authors' own work on the preparation and elinical use of concentrates of antihæmophilic globulin and Christmas factor, and the use of these is fully described.

It is a pleasure to record that the standard of production is vastly improved. In spite of the inclusion of much new material, the book has been kept to the same size, partly by the use of slightly smaller print and by the omission of the summaries at the end of each chapter, which served no very useful purpose in the previous editions. The figures are now excellent and the biblio. graphy is greatly improved by being collected in a single alphabetical series; only the index leaves room for considerable improvement in subsequent editions. This book remains unchallenged in its field; it is not only indispensable to all workers on blood coagulation, but also so well balanced and readable as to be highly recommended to non-specialists.

R. M. Hardrsty

\section{TISSUE TRANSPLANTATION}

Ciba Foundation Symposium on Transplantation

Edited by G. E. W. Wolstenholme and Margaret P. Cameron. Pp. xii +426. (London: J. and A. Churchill, Ltd.. 1962.) $56 s$.

7 HIS volume is dedicated to the memory of the late

Peter A. Gorer, whose brilliant work on the serology and serological geneties of homograft reactions is briefly surveyed in the Chairman's opening remarks. In closing these remarks Prof. P. B. Medawar states " . . . let us not forget that we are still quite ignorant of the proximate cause of the death of any homograft" and ". . . we know of no harmless and lastingly effective way to subdue the homograft reaction in adult animals".

The sixteen papers presented at this symposium contain little that offers immediate hope of negating these statements although obvious progress is being made in the understanding of some of the immunological aspects of tissue transplantation. The opening papers deal with the considerable recent progress made in the difficult problem of identification and characterization of tissue antigens. Further practical progress is reported in the attempts to ameliorate runt disease in mice. Notable contributions to the theoretical advance are the papers presenued on the role of the thymus, the quantitative nature of immune tolerance and an investigation into the clonal selection theory.

In view of the increasingly successful efforts being made in the field of human organ transplantation, it is disap. pointing to find that, with one exception, the communications are confined to studies on small rodents. Nevertheless, the symposium is of obvious value to any worker in the field of tissue transplantation, as a convenient summary of recent progress in the non-clinical aspects of this subject.

W. J. Dempster

\section{NATURAL AND SYNTHETIC COLOURING MATTERS}

Recent Progress in the Chemistry of Natural and Synthetic Colouring Matters and Related Fields

Edited by T. S. Gore, B. S. Joshi, S. V. Sunthankar and B. D. Tilak. Pp. xxvii +659 . (New York: Academic Press, Inc.; London: Academic Press, Inc. (London), Ltd., 1962.) 171s. $6 d$.

7 HE book contains a collection of papers and reviews most of which deal with recent progress in the ehemistry of natural and synthetic colouring matters, but a fow are concerned with the wider field of plant chemistry and general organic chemistry. The authors in many cases are of world-wide reputation, both in the field of theoretical and experimental organic chemistry. Some of the papers follow the pattern of those found in the journals of the various chemical societies, with the excep. tion that all the authors start with a reasonable introduc. tion to their subject-matter, a thing which is rarely found in some present-day journals, thus making it easier for the reader to follow and understand the work under discussion. Some of the papers even go so far as to include an experimental section along with analytical results. In the reviews, a particular field is surveyed over a number of years and in the majority of cases right up to 1960. In many instances suggestions are made for further investigations which still require to be earried out in the reviewed field.

About one-third of the book is devoted to the chemistry of oxygen heterocyclic and related natural occurring compounds, while a quarter deals with various interesting synthetic dyes and intermediates, the preparation and properties of which, in a number of cases, are treated from a physical chemical point of view. I am pleased to note that the editors have not allowed the reviews concerned with the chemistry of dyes to become pages of recipes. Other parts of the book are concerned with some topics found in the following fields; the azulenes, diterpenes, alkaloids and carcinogenic hydrocarbons. The book succeeds in presenting an up-to-date and complete account of the included topics in the light of modern theory, the subject-matter being presented in a clear and concise fashion. In a book of this type it is quite easy for the editors to omit a topic which some readers might believe should have been included, but I think that they have made a very good selection.

Though most of the book is concerned with up-to-dates work, the occasional review describes some older significant and outstanding work in a particular field, especially among some of the naturally occurring pigments, an example being the work of Hooker on the chemistry of lapachol. A few pages are even devoted to Hooker himself, an extraordinary man and a true master of experimental investigation.

It follows, therefore, that the potential market for this book will be limited, but for specialists in the fields men. tioned, and for libraries it will provide a valuable summary 